\title{
RADIOCARBON DATING OF MILLIMOLE-SIZED GASEOUS SAMPLES
}

\author{
DUŠAN SRDOČ, BOGOMIL OBELIĆ and NADA HORVATINČIĆ
}

Ruđer Bošković Institute, Zagreb, POBox 1016, Yugoslavia

ABSTRACT. As an alternative to the accelerator technique, a simple, compact, small counter system has been developed and tested for routine ${ }^{14} \mathrm{C}$ dating. Our small counter is an all-metal design made of the OFHC copper with quartz supports

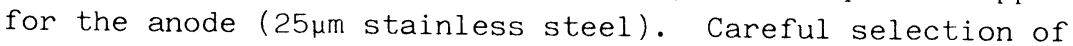
materials for the counter construction was made based on the measurements of the alpha contamination. Methane as the counter filling gave better resolution and gas gain stability, whereas $\mathrm{CO}_{2}$ gave lower background counting rate and it was easier to prepare and to handle. The long term run using $\mathrm{CH}_{4}$ showed that the gas gain remained stable within $1-2 \%$ for months after the initial drop which followed the counter filling. A 7-day counting period was sufficient to achieve a $3 \%$ relative standard deviation which was considered acceptable for routine dating of younger samples.

\section{INTRODUCTION}

\section{4} C dating of small samples containing carbon in the millimole range ( $\sim 12 \mathrm{mg}$ ) is obviously needed (Sayre et al, 1981; Currie, Klouda, and Cooper, 1980). The very promising accelerator technique is presently in a developmental stage and an increasing number of ${ }^{14} \mathrm{C}$ laboratories are trying to cope with milligram-sized samples. The seemingly inherent drawbacks associated with the samll counter technique are 1) very long counting time, and 2) a poor sample-to-background count ratio. Whereas low counting rate is a direct result of reduced sample size which cannot be avoided, the sample-to-background count ratio can be improved. A better anticoincidence shield in the form of a large NaI crystal (Sayre et al, 1981) is one choice, although very expensive. Careful selection of counter construction materials, described here, also helps but the figure of merit $S^{2} / B$ for small counters must still be made comparable to that for a standard counter. 
The aim of this paper is to show that the construction and operation of a counting system capable of measuring small samples is within the reach of normally equipped ${ }^{14} \mathrm{C}$ laboratory. Several specific features pertinent to small counter technology are described as well as results of measurements.

THE SMALL COUNTER DESIGN

Our $5 \mathrm{ml}$ counter (fig 1 ) is an all-metal design made of OFHC copper with quartz supports for the anode $(25 \mu \mathrm{m}$ stainless steel).

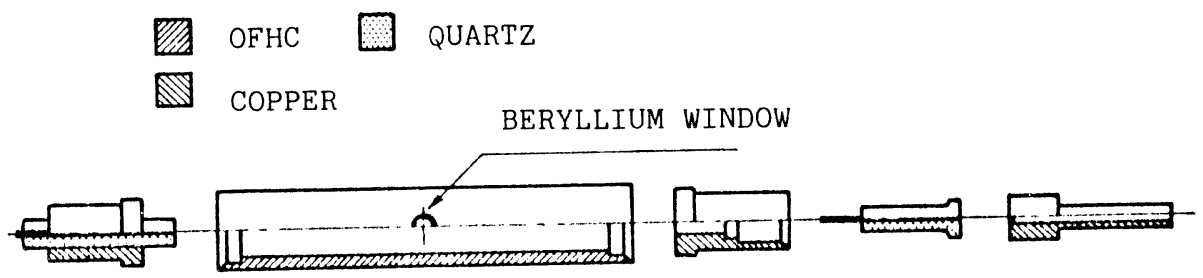

Fig. 1 Schematic of the small ( $5 \mathrm{ml}$ ) proportional counter. Anode: $25 \mu \mathrm{m}$ stainless steel wire; metal parts: OFHC copper; insulators: quartz; vaccum tight joints: Torr-seal.

Pumping and filling is performed via $2 \mathrm{~mm}$ i d copper tubing which is permanently sealed after filling the counter. No valves or stopcocks are used to maintain the gas inside the counter at the required high-level purity over long counting periods. The counter can withstand a moderate bake-out as well as immersion in liquid $\mathrm{N}_{2}$ to transfer the counting gas quantitatively from the mani-fold to the counter. The vacuum-tight joint between quartz insulators and metal parts of the counter is obtained by applying Torr-seal epoxy resin. No adverse effect on counter gas gain stability has been observed in counters assembled with the aid of Torr-seal resin. The counter design makes possible a direct noise-free coupling to the FET pre-amplifier. The negative voltage is applied to the counter cathode, ie, to the copper casing. The assembled counter and pre-amplifier make a compact unit 
which is positioned in the center of the shielding system consisting of the guard counter and a cylindrical lead shield, $25 \mathrm{~cm}$ thick. The guard counter is made of 2 concentric steel tubings separated into 16 sections by metal sheets. Each section represents an individual Geiger counter. The guard counter is filled with $1.5 \mathrm{~atm}$ of argon with $2 \%$ butane as a quenching admixture.

Materials for the counter construction were carefully selected to avoid natural or man-made radioactive contamination. Many materials were tested for alpha activity which indicates natural contamination. The results are presented elsewhere (Srdoč, in press). Construction materials included OFHC copper, mild steel, epoxy resin, and quartz as the radioactively cleanest material. Stainless steel and high-purity tin solder could not be avoided in small quantities even though their.alpha activity was somewhat higher, although far from that of aluminium or commercial tin solder, which should be avoided in any case. Natural contamination of materials commonly used in the low level technique is presented in table 1 .

\section{SMALL COUNTER PERFORMANCES}

We tested methane and carbon dioxide for small counter filling. Synthesis of methane requires an additional step in gas preparation. Methane is less susceptible to electronegative impurities and, thus, more convenient for prolonged measureinents. However, methane gives higher background count due to proton recoils as opposed to $\mathrm{CO}_{2}$, which is, on the other hand, more sensitive to gaseous impurities. The counter resolution for low-energy photons $(5.9 \mathrm{keV} \mathrm{X}$-ray from $\left.{ }^{55} \mathrm{Fe}\right)$ and the constancy of the peak position are excellent indicators of gas properties. The results of $11 / 2$ months of testing the stability of the sealed-off counter are shown in figure 2 along with the spectrum of $55 \mathrm{Fe}$ source $(5.9 \mathrm{keV})$ measured 47 days after sealing the counter.

The efficiency of the counter and the ratio $\mathrm{S}^{2} / \mathrm{B}$ depend also on the lower and upper discriminator settings of the electronic counting system. A single-channel analyzer (SCA) with a wide-open window must be properly adjusted to obtain the optimal $\mathrm{S}^{2} / \mathrm{B}$ ratio. The spectra shown in figure 3 implied the total and residual background pulse height 

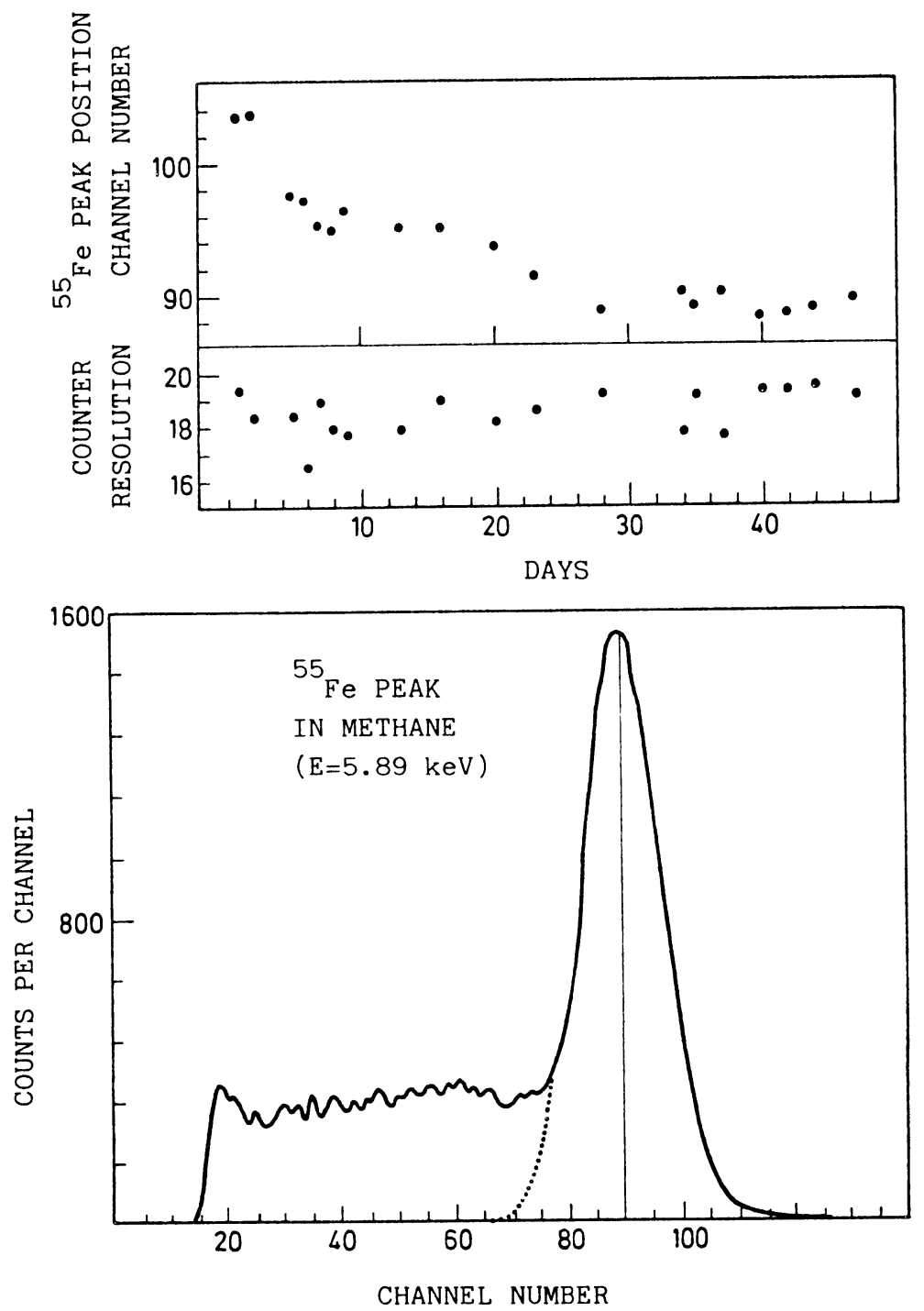

Fig. 2 Properties of small proportional counter: ${ }^{55}$ Fe peak position and counter resolution vs time (top). $55 \mathrm{Fe}$ spectrum 47 days after filling the counter (bottom). Counter gas: $\mathrm{CH}_{4}$. 

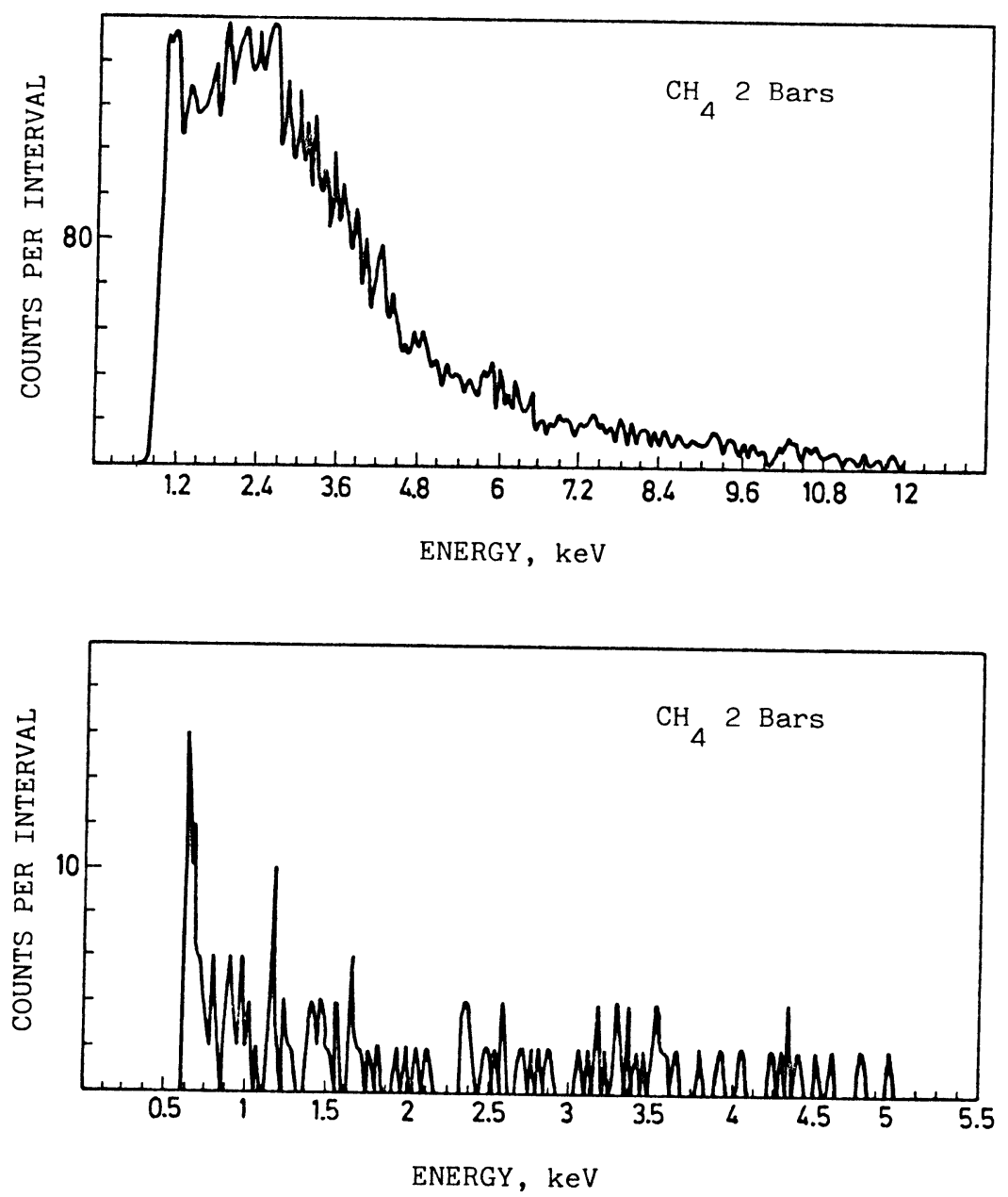

Fig. 3 Total (coincident) and residual (anticoincident) background pulse height distribution in small proportional counter filled with $\mathrm{CH}_{4}$ (2 Bars). Top: Total background spectrum. Bottom: Residual background spectrum, after elimination of coincident pulses. 
TABLE 1. Surface activity of various materials

\begin{tabular}{lll}
\hline Material & $\begin{array}{c}\text { Technical description, } \\
\text { source or/and } \\
\text { provenience of samples }\end{array}$ & $\begin{array}{c}\text { Alpha activity } \\
\mathrm{dm}^{-2} \mathrm{~h}^{-1} \pm 10 \%\end{array}$ \\
\hline
\end{tabular}

M e t a 1 s

\begin{tabular}{|c|c|c|}
\hline Aluminum & Foil, $25 \mu \mathrm{m}$, Reynolds, Wrap & 23.5 \\
\hline Brass & $\begin{array}{c}\text { Sheet, } 1 \mathrm{~mm} \text {, commercial, } \\
\text { unknown origin }\end{array}$ & 7.0 \\
\hline Copper & $\begin{array}{l}\text { Cast metal, OFHC, J Mathey, } \\
\text { London, UK }\end{array}$ & 3.0 \\
\hline Lead & $\begin{array}{c}\text { Sheet, 3mm, commercial, } \\
\text { Mežice, YU }\end{array}$ & 11.0 \\
\hline Old lead & $\begin{array}{c}\text { Cast metal, Roman anchor, } \\
\text { Adriatic Sea }\end{array}$ & 2.2 \\
\hline $\begin{array}{l}\text { Stainless } \\
\text { steel }\end{array}$ & $\begin{array}{c}\text { Rolled sheet, } 0.5 \mathrm{~mm} \text {, Schoeller- } \\
\text { Bleckmann, Vienna, Austria }\end{array}$ & 6.0 \\
\hline Steel & $\begin{array}{c}\text { Rolled sheet, commercial, } \\
\text { Zenica, YU }\end{array}$ & 2.6 \\
\hline $\begin{array}{l}\text { Solder, } \\
\text { soft }\end{array}$ & $\begin{array}{l}\text { Tin-based soft solder, CN-7 } \\
\text { Duduco, Pforzheim, W Germany }\end{array}$ & 600 \\
\hline Lucite & $\begin{array}{c}\text { Clear tubing, Polypenco, } \\
\text { London, UK }\end{array}$ & 1.4 \\
\hline Teflon & $\begin{array}{l}\text { Electrical grade, The Edison } \\
\text { Swan Co, London, UK }\end{array}$ & 1.6 \\
\hline
\end{tabular}

distributions. The total (coincident) background spectrum has a peaked pulse-height distribution because most charged particles cross the counter volume. In such cases, the spectrum reflects counter geometry and gas density. The 
residual background (anticoincidence) spectrum is relatively flat, as is the sample plus residual background spectrum. However, the extremely low counting rate ( 0.1CPM) hampers the pulse height analysis so badly that reliable spectra of ${ }^{14} \mathrm{C}$ beta particles in a small counter cannot be obtained without a much stronger ${ }^{14} \mathrm{C}$ source. Presently, we use the spectra calibrated with ${ }^{55} \mathrm{Fe}$ to set the lower discriminator level at $0.3 \mathrm{keV}$, which is well above the electronic noise and the upper level at $20 \mathrm{keV}$. Most truncated ${ }^{14} \mathrm{C}$ beta particle tracks are within these limits. Further optimization of discriminator settings will be possible upon more precise analysis of ${ }^{14} \mathrm{C}$ spectrum that we hope to measure soon.

Samples containing 10 to $100 \mathrm{mg}$ of carbon were combusted by the conventional technique used in organic chemistry. $\mathrm{CO}_{2}$ was purified to a high degree, applying the technique developed in this laboratory (Srdoč and Sliepčević, 1963). Catalytic hydrogenation of $\mathrm{CO}_{2}$ at $450^{\circ} \mathrm{C}$ cover $\mathrm{Ru}$ catalyst was applied to obtain methane. During the experimental stage, both were used for counting purpose. Most of our measurements consist of background and oxalic acid (NBS) standard samples as well as fractions of large samples measured by our conventional ${ }^{14} \mathrm{C}$ system, to check the reliability of the small counter. A 7-day counting period was sufficient to achieve $3 \%$ relative standard deviation which was considered acceptable for testing purposes. Table 2 shows the properties of our small volume counter.

TABLE 2. Properties of the $5 \mathrm{ml}$ counter

\begin{tabular}{lccc}
\hline $\begin{array}{l}\text { Counting } \\
\text { gas }\end{array}$ & $\begin{array}{c}\text { Milimoles } \\
\text { of carbon }\end{array}$ & $\begin{array}{c}\text { Oxalic (NBS) } \\
\text { standard CPM (net) }\end{array}$ & $\begin{array}{c}\text { Background } \\
\text { CPM }\end{array}$ \\
\hline $\mathrm{CO}_{2}$ & 1 & $0.14 \pm 0.04$ & $0.084 \pm 0.025$ \\
$\mathrm{CH}_{4}$ & 1 & $0.15 \pm 0.04$ & $0.096 \pm 0.030$ \\
\hline
\end{tabular}


Our goal is to replicate the small counter and set up a honeycomb-like structure with 7 counters in anticoincidence. Thus, the output of the small counter assembly would be comparable to the conventional ${ }^{14} \mathrm{C}$ dating system in terms of number of processed samples per year and the accuracy of measurement.

\section{REFERENCES}

Currie, LA, Klouda, GA, and Copper, JA, 1980, Mini-radiocarbon measurements, chemical selectivity and the impact of man on environmental pollution and climate, in Stuiver $\mathrm{M}$ and $\mathrm{Kra}$, RS, eds, Internatl ${ }^{14} \mathrm{C}$ conf, 10th Proc: Radiocarbon, v 22, no. 2, p 349-362.

Sayre, EV, Harbottle, G, Stoenner, RW, Otlet, RL, and Evans, GV, 1981, Small gas proportional counters for the ${ }^{14} \mathrm{C}$ measurement of very small samples, in Methods of low-level counting and spectrometry, Proc: Berlin, IAEA, p 393-407.

Srdoč, D, in press, Surface emission of alpha particles from materials used in low-level radioactivity technique, in Internatl conf on low-level activity measurements and applications, 2nd Proc: High Tatras, Czechoslovakia.

Srdoč, D, and Sliepčević, A, 1963, Carbon dioxide proportional counter; effects of gaseous impurities and gas purification method: Jour Appl Radiation Isotopes, v 14, p 481-488 . 